\title{
Dynamics of explosive degassing of magma: Observations of fragmenting two-phase flows
}

\author{
H. M. Mader, J. C. Phillips and R. S. J. Sparks \\ Department of Geology, University of Bristol, Bristol, England
}

\section{B. Sturtevant}

Graduate Aeronautical Laboratories, California Institute of Technology, Pasadena

\begin{abstract}
Liquid explosions, generated by rapid degassing of strongly supersaturated liquids, bave been investigated in the laboratory with a view to understanding the basic physical processes operating during bubble nucleation and growth and the subsequent behavior of the expanding two-phase flow. Experiments are carried out in a shock tube and are monitored by high-speed photography and pressure transducers. Theoretical $\mathrm{CO}_{2}$ supersaturations up to 455 times the ambient saturation concentration are generated by a chemical reaction; $\mathrm{K}_{2} \mathrm{C}_{3} \mathrm{O}_{3}$ solution is suddenly injected into an excess of HCl solution in such a way as to mix the two solutions rapidly. Immediately after the injection event, a bubble nucleation delay of a few milliseconds is followed by rapid nucleation and explosive expansion of $\mathrm{CO}_{2}$ bubbles forming a highly heterogeneous foam. Enhanced diffusion due to advection in the llow coupled with continuous mixing of the reactants, and hence on-going bubble nucleation after injection, generates an increasingly accelerating flow until the reactants become depleted at peak accelerations of around $150 \mathrm{~g}$ and velocities of about $15 \mathrm{~m} \mathrm{~s}^{-1}$. Stretching of the accelerating two-phase mixture enhances the mixing. Liberation of $\mathrm{CO}_{2}$ vapor is spatially inhomogeneous leading to ductile fragmentation occurring throughout the flow in regions of greatest gas release as the consequence of the collision and stretching of fluid streams. The violence of the eruptions is controlled by using different concentrations of the $\mathrm{HCl}$ and $\mathrm{K}_{2} \mathrm{C}_{3} \mathrm{O}_{3}$ solutions, which alters the $\mathrm{CO}_{2}$ supersaturation and yield and also the efficiency of the mixing process. Peak acceleration is proportional to theoretical supersaturation. Pressure measurements at the base of the shock tube show an initial nucleation delay and a pressure pulse related to the onset of explosive bubble formation. These chemically induced explosions differ from liquid explosions created in other experiments. In explosions caused by sudden depressurization of $\mathrm{CO}_{2}$-saturated water, the bubbles nucleate uniformly throughout the liquid in a single nucleation event. Subsequent bubble growth causes the two-phase mixture to be accelerated upward at nearly constant accelerations. Explosively boiling liquids, in which helerogeneous nucleation is suppressed, experience an evaporation wave which propagates down into the liquid column at constant average velocity. Fragmentation occurs at the sharply delined leading edge of the wavefront. The chemical fows effectively simulate highly explosive volcanic eruptions as they are comparable in terms of flow densities, velocilies, accelerations, and in the large range of scales present. The large accelerations cause strong extensional strain and longitudinal deformation. Comparable deformation rates in volcanic systems could be sufficient to approach conditions for britle fragmentation. Tube pumice is a major component of plinian deposits and ignimbrites and preserves evidence of accelerating flow conditions.
\end{abstract}

\section{Introduction}

The flow conditions that occur in explosive volcanic eruptions are known to be extreme. High-viscosity magma containing small amounts of dissolved gas becomes strongly supersaturated on approaching the Earth's surface. Gas bubbles nucleate and grow explosively and the magma disintegrates into a two-phase mixture of gas and pyroclasts that accelerates to velocities of order of a few hundred meters per second along volcanic conduits [Wilson et al., 1980; Dobran, 1992]. The timescales for these processes

Copyright 1996 by the American Geophysical Union.

Paper number 95JB02515.

$0148-1227 / 96 / 95 \mathrm{JB}-02515 \$ 05.00$ are very short. For example, in the plinian eruption of Mount St. Helens on May 18, 1980, estimates of chamber depth, magma discharge rates, conduit dimensions and volatile contents [Carey et al., 1990] constrain the time that it takes for an individual parcel of magma to move from the chamber to the Earth's surface as about $10 \mathrm{~min}$. Due to pressure variations most bubble growth is confined to the uppermost parts of the magma column so the timescale for explosive degassing must be substantially less. Estimates from modeling studies [e.g., Kieffer, 1981; Dobran. 1992; Proussevitch et al., 1993; Sparks et al., 1994] suggest that timescales for prefragmentation bubble growth in plinian eruptions are of order 10 to $100 \mathrm{~s}$.

Explosive volcanic flows are unlikely to be observed directly. Therefore the processes involved can only be studied by theoretical modeling, simulation in analogue experiments, or 
examination of the geological record. All three approaches have their merits and limitations. Computer simulations [e.g., Sparks, 1978; Dobran, 1992; Proussevitch et al., 1993] cannot yet take into account the very wide range of scales and interacting processes that characterize volcanic flows and are thus required to make approximations which preclude them from recognizing the full richness of the physical phenomena that occur. Experimental studies in analogue systems can identify complex phenomena that are as yet beyond the capacity for numerical simulation. Experimental simulations of high-speed flows have already provided new insights into explosive volcanism through the study of overpressured jets [Kieffer and Sturtevant, 1984], vaporization of superheated liquids [Hill and Sturtevant, 1990], and the decompression of two-phase solid-gas beds [Anilkumar et al., 1993]. However, there remain important problems of scaling laboratory experiments to the large-scale natural flows, particularly in high-speed two-phase flows where scaling laws are not well established. Both experimental and theoretical simulations provide the underlying conceptual framework for interpretation of observations. Geological data and observations provide the motivation and constraints for developing theory and choosing useful experimental analogues to study.

This paper describes experiments on the hehavior of strongly supersaturated aqueous solutions formed by chemical reaction due to mixing reactant fluids in a shock tube. In the experiments,
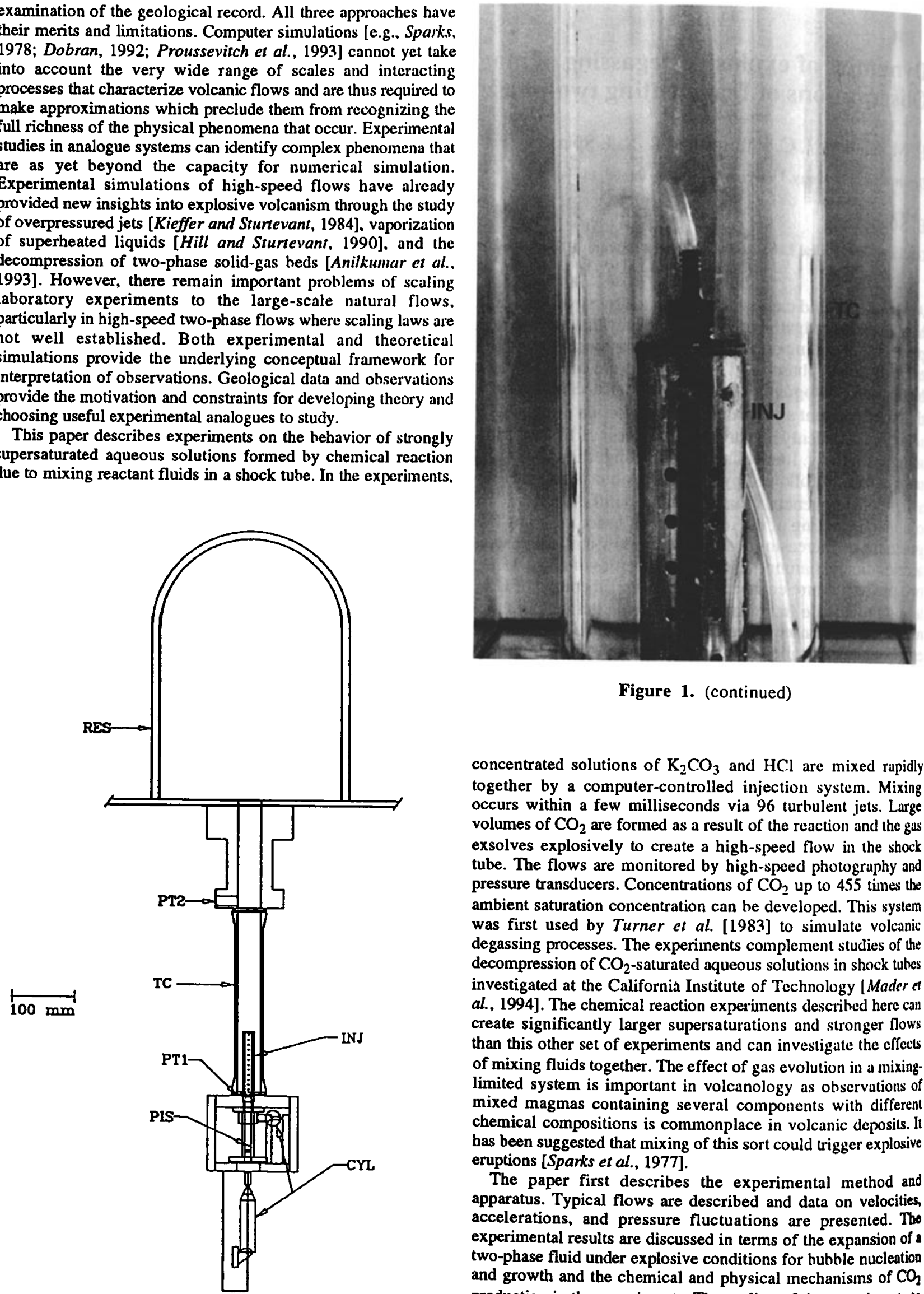

Figure 1. (continued)

concentrated solutions of $\mathrm{K}_{2} \mathrm{CO}_{3}$ and $\mathrm{HCl}$ are mixed rapidly together by a computer-controlled injection system. Mixing occurs within a few milliseconds via 96 turbulent jets. Large volumes of $\mathrm{CO}_{2}$ are formed as a result of the reaction and the gas exsolves explosively to create a high-speed flow in the shock tube. The flows are monitored by high-speed photography and pressure transducers. Concentrations of $\mathrm{CO}_{2}$ up to 455 times the ambient saturation concentration can be developed. This system was first used by Turner et al. [1983] to simulate volcunic degassing processes. The experiments complement studies of the decompression of $\mathrm{CO}_{2}$-saturated aqueous solutions in shock tuhes investigated at the California Institute of Technology [Mader et al., 1994]. The chemical reaction experiments described here can create significantly larger supersaturations and stronger flows than this other set of experiments and can investigate the effects of mixing fluids together. The effect of gas evolution in a mixinglimited system is important in volcanology as observations of mixed magmas containing several components with different chemical compositions is commonplace in volcanic deposits. It has been suggested that mixing of this sort could trigger explosive eruptions [Sparks et al., 1977].

The paper first describes the experimental method and apparatus. Typical flows are described and data on velocities, accelerations, and pressure fluctuations are presented. The experimental results are discussed in terms of the expansion of a two-phase fluid under explosive conditions for bubble nucleation and growth and the chemical and physical mechanisms of $\mathrm{CO}_{2}$ production in the experiments. The scaling of the experiments to volcanic flows and the implications for explosive eruption

Figure 1. (a) Scale drawing of the experimental apparatus. (b) Photograph of the injector (INJ) sited in the emply test cell (TC). 




Figure 2. Schematic diagram of the instrumentation associated with the experimental apparatus. Prior to an experiment, the injector (INJ) is in the closed position. The reactants are stored inside the injector and in the test cell (TC). The drain from the injector is necessary to allow air to flow out of the injector during the filling process. An experiment then proceeds as follows. (1). The camera, a Ilycam S-2 rotating prism 16-mm highspeed ciné camera, starts to run. This camera has filming rates up to 10.000 frames per second (fps). When the camera has reached the desired frame rate, usually $5000 \mathrm{fps}$ in these experiments, it sends an electronic trigger to the computer. (2). The computer then immediately commences data collection from the pressure transducers PT1 and PT2 via the analog to digital converter ADC. Sampling is performed at $10 \mathrm{kHz}$. The transducers have a rise time of $1 \mu \mathrm{s}$. (3). The computer then opens the injector by activating solenoid 1 (SOL1) via relay 1 (REL1) thereby causing the pneumatic cylinder (CYL1) to rotate the inner cylinder of the injector. Subsequent activation of solenoid 2 (SOL2) via relay 2 (REL2) causes the other pneumatic cylinder (CYL2) to force the piston (PIS) upward and the reactant out of the injector. The two reactants are mixed in the test cell and the reaction proceeds. The solenoid valves have a response time of $5 \mathrm{~ms}$, and from our experimental results we estimate that it takes 12 $\mathrm{ms}$ to open the holes and $14 \mathrm{~ms}$ to inject the reactant. (4). The camera switches off automatically when it runs out of film. The computer ceases data collection after a specified time, returns the piston, and closes the injector.

\section{Apparatus}

The apparatus used in the experiments is shown in Figure 1. It consists of a glass test cell (TC; ID $37 \mathrm{~mm}$, wall thickness $6 \mathrm{~mm}$ ) that is connected to a dome-shaped reservoir (RES; ID $300 \mathrm{~mm}$, height $420 \mathrm{~mm}$, wall thickness $8 \mathrm{~mm}$ ) made of toughened glass. The test cell is supplied in 300 -mm lengths and up to two sections are used in these experiments.

An experiment is initiated by rapidly mixing two chemical solutions thereby allowing the chemical reaction and hence gas evolution to take place. The mixing is achieved by means of an injector (INJ) that is sited at the base of the test cell (sce Figure 1b). The injector has been designed to satisfy several critcria. First, the reactants must be kept apart prior to an experiment. Second, the injection of one reactant into the other must he fast and done in a way that maximizes the mixing. Third, the mixing process itself must not introduce any significant vertical or borizontal velocity components. Finally, the geometry of the injector must be such that it does not impede the progress of the expanding two-phase flow.
The injector consists of a stainless steel outer cylinder (OD 19 $\mathrm{mm}$ ) that fits tightly over a polytetrafluoroethylene (PTFE) inner cylinder (OD $16.6 \mathrm{~mm}$, wall thickness $3.5 \mathrm{~mm}$ ). Both cylinders have an identical set of 96 boles drilled in them ( 12 rows of 8 holes, OD $2 \mathrm{~mm}$, distance between holes $7.5 \mathrm{~mm}$ ). The holes can be opened by rotating the inner cylinder with respect to the outer cylinder, which is fixed, thereby aligning the holes.

Prior to an experiment, one reactant is fed into the injector and thus resides inside the PTFE inner cylinder. The other reactant fills the annular region in the test cell surrounding the injector. In the initial, closed position, the inner and outer cylinders are positioned so that the holes are not aligned and a seal is formed which prevents contact between the reactants. On initiation of the experiment, the inner cylinder is rotated with respect to the fixed outer cylinder to align the holes. The reactant stored inside the inner cylinder is then expelled as 96 turbulent jets by a piston (PIS) sited within the inner cylinder at the base of the injector. The motions of the inner cylinder and of the piston are performed by pneumatic cylinders (CYL) which are thenselves computer controlled (see Figure 2). 




Figure 3. Plan view of the apparatus showing the relative positions of the light sources (LS), test cell (TC), and camera (CAM). The light sources all consist of $2-\mathrm{kW}$ halogen light bulbs sited in $360 \mathrm{~mm} \times 360 \mathrm{~mm}$ metal reflectors. The test cell is back lit by LS1 through a ground glass screen (GGS) and front lit hy LS2 and LS3, which have no screens. The test cell itself is surrounded by a water jacket (WJ; not shown in Figures 1 and 2) which removes much of the optical distortion caused hy the cylindrical lens of the liquid column in the test cell.

Bubble nucleation and growth and the subsequent motion of the flow front are recorded using high-speed motion photography. The test cell is illuminated from behind by a $2-\mathrm{kW}$ halogen light bulb and from the front using two further $2-\mathrm{kW}$ halogen light bulbs (see Figure 3). This lighting enables us to obtain a 100-mm depth of field thereby ensuring that the whole flow is in sharp focus.

During an experiment, the pressure exerted by the expanding foam flow is measured at the base and top of the test cell by piezoelectric pressure transducers PT1 and PT2 (sec Figures 1 and 2). These transducers are mounted flush with the test cell base and wall and so do not obstruct the flow in any way. Prior to an experiment a very small underpressure was created within the reservoir ( $80 \mathrm{kPa}$ absolute) using a small diaphragm pump. This prevented the dome from being lifted off its base by the force of the explosion and thus ensured that the chemicals remained confined within the apparatus.

\section{Method}

Experiments were carried out using $\mathrm{K}_{2} \mathrm{CO}_{3}$ solutions ( $4.5 \mathrm{M}, 6$ $M)$ and $\mathrm{HCl}$ at three concentrations $(6 M, 9 M, 12 M)$. In all cases the $\mathrm{K}_{2} \mathrm{CO}_{3}$ was first fed into the injector and then injected into the $\mathrm{HCl}$ which filled the annular region around the injector. The geometry of the apparatus results in the injected volume of saturated $\mathrm{K}_{2} \mathrm{CO}_{3}$ solution ( $3.96 \mathrm{~mL}$ ) being much less than the volume of $\mathrm{HCl}(80 \mathrm{~mL}$ to $100 \mathrm{~mL})$ in the test cell. Consequently, the $\mathrm{K}_{2} \mathrm{CO}_{3}$ can always be fully neutralized as there is always a large excess of $\mathrm{HCl}$ (see (1)). This means that the potential $\mathrm{CO}_{2}$ yield is controlled only by the concentration of the $\mathrm{K}_{2} \mathrm{CO}_{3}$ and is $0.024 \mathrm{~mol}$ in all experiments using saturated $\mathrm{K}_{2} \mathrm{CO}_{3}(6 M)$. The effect of varying $\mathrm{CO}_{2}$ yield was investigated by injecting $4.5 \mathrm{M}$ $\mathrm{K}_{2} \mathrm{CO}_{3}$ into $12 \mathrm{M} \mathrm{HCl}$ producing a potential $\mathrm{CO}_{2}$ yield of 0.018 mol. The theoretical supersaturation $S$ produced by the chemical reaction is taken to be the ratio of the maximum possible concentration of $\mathrm{CO}_{2}$ during mixing of the reactants with the ambient saturation concentration of $\mathrm{CO}_{2}$ prior to mixing. Principal observations of interest for these foum flows are the height of the flow front as a function of tine, which is a measure of the volume of gas evolved, and the pressure exerted by the flow, which is a measure of the thrust experienced by the flow and the pressure in the fluid as the gas is exsolved.

The position of the flow front is recorded by the movie camer. The vertical frame dimension of the camera is typically $130 \mathrm{~mm}$ in real space. Thus to track the flow front all the way up the test cell, which is $600 \mathrm{~mm}$ long, five runs of the same experiment were performed with the camera mounted at different heights. In each case, a scale inside the water jacket was used to locate the flow front within the field of view and the height of the zero of the scale above the test cell base was measured. A set of five runs with the same experimental conditions but with the camera mounted at different heights is called a "series" in this paper. Table 1 summarizes the properties of the fluids and the experimental conditions for each of the series performed.

The experiments are computer controlled and the instrumentation has been described in the previous section (see in particular Figure 2). Pressure measurements at the shock tuhe base and top were also recorded automatically for each experiment, except for the experimental series 2 and 5 . The lack of pressure data for these runs was the result of pressure transducer failure in the corrosive $\mathrm{HCl}$ environment. The pressure traces were also helpful in determining the reproducibility of experiments within a given series and thus provided a check on the validity of combining data sets in a series.

\section{Experimental Results}

\section{General Observations of Expanding Flows}

It is important in these experiments that the injector does not introduce any significant components of flow in either the vertical or horizontal direction. This was confirmed by dummy experiments in which water was injected into water. The fluid

Table 1. Experimental Conditions

\begin{tabular}{|c|c|c|c|c|c|c|c|c|c|}
\hline \multirow{4}{*}{ Series } & \multirow{4}{*}{$\begin{array}{l}\text { Concentration } \\
\text { of Reactant in } \\
\text { Injector, } \\
\text { mol / } \mathrm{LK}_{2} \mathrm{CO}_{3}\end{array}$} & \multirow{4}{*}{$\begin{array}{l}\text { Concentration } \\
\text { of Reactant in } \\
\text { Test Cell, } \\
\text { mol / L HCl }\end{array}$} & \multirow{4}{*}{$\begin{array}{c}\text { Theoretical } \\
\text { Supersaturation } \\
\text { Ratio, S }\end{array}$} & \multirow{2}{*}{\multicolumn{2}{|c|}{$\begin{array}{l}\text { Potential } \\
\mathrm{CO}_{2} \text { Yield }\end{array}$}} & \multirow{4}{*}{$\begin{array}{l}\mathrm{K}_{2} \mathrm{CO}_{3} \\
\text { Viscosity } \\
\text { at } 20^{\circ} \mathrm{C} \\
\times 10^{-3} \mathrm{Pas}\end{array}$} & \multirow{3}{*}{$\begin{array}{l}\mathrm{K}_{2} \mathrm{CO}_{3} \\
\text { Densily } \\
\text { at } 20^{\circ} \mathrm{C}\end{array}$} & \multirow{4}{*}{$\begin{array}{c}\mathrm{HCl} \\
\text { Viscosity } \\
\text { at } 20^{\circ} \mathrm{C} \\
\times 10^{-3} \mathrm{Pas}\end{array}$} & \multirow{4}{*}{$\begin{array}{c}\mathrm{HCl} \\
\text { Density } \\
\text { at } 20^{\circ} \mathrm{C}, \\
\times 10^{3} \mathrm{~kg} / \mathrm{m}^{3}\end{array}$} \\
\hline & & & & & & & & & \\
\hline & & & & \multirow[b]{2}{*}{ Mole } & \multirow[b]{2}{*}{ L at RTP } & & & & \\
\hline & & & & & & & $\times 10^{3} \mathrm{~kg} / \mathrm{m}^{3}$ & & \\
\hline 1 & 6 & 6 & 303 & 0.024 & 0.58 & 11.93 & 1.59 & 1.37 & 1.09 \\
\hline 2 & 6 & 6 & 303 & 0.024 & 0.58 & 11.93 & 1.59 & 1.37 & 1.09 \\
\hline 3 & 6 & 9 & 390 & 0.024 & 0.58 & 11.93 & 1.59 & 1.65 & 1.14 \\
\hline 4 & 6 & 12 & 455 & 0.024 & 0.58 & 11.93 & 1.59 & 2.10 & 1.18 \\
\hline 5 & 6 & 12 & 455 & 0.024 & 0.58 & 11.93 & 1.59 & 2.10 & 1.18 \\
\hline 6 & 4.5 & 12 & 390 & 0.018 & 0.43 & 5.26 & 1.44 & 2. 10 & 1.18 \\
\hline
\end{tabular}

The viscosity and density values are taken from Weast [1983]. No uncertainties are quoted for these values. The uncertainty in the concentration of the solutions as made up for the experiments is likely to be about $\pm 1 \%$ primarily due to a small random error in the volume measurements. Along with an cslimated uncertainty of no more than $\pm 1 \%$ in the injected volume, this translates into an error on the potential $\mathrm{CO}_{2}$ yiclds of at most $\pm 2 \%$. 

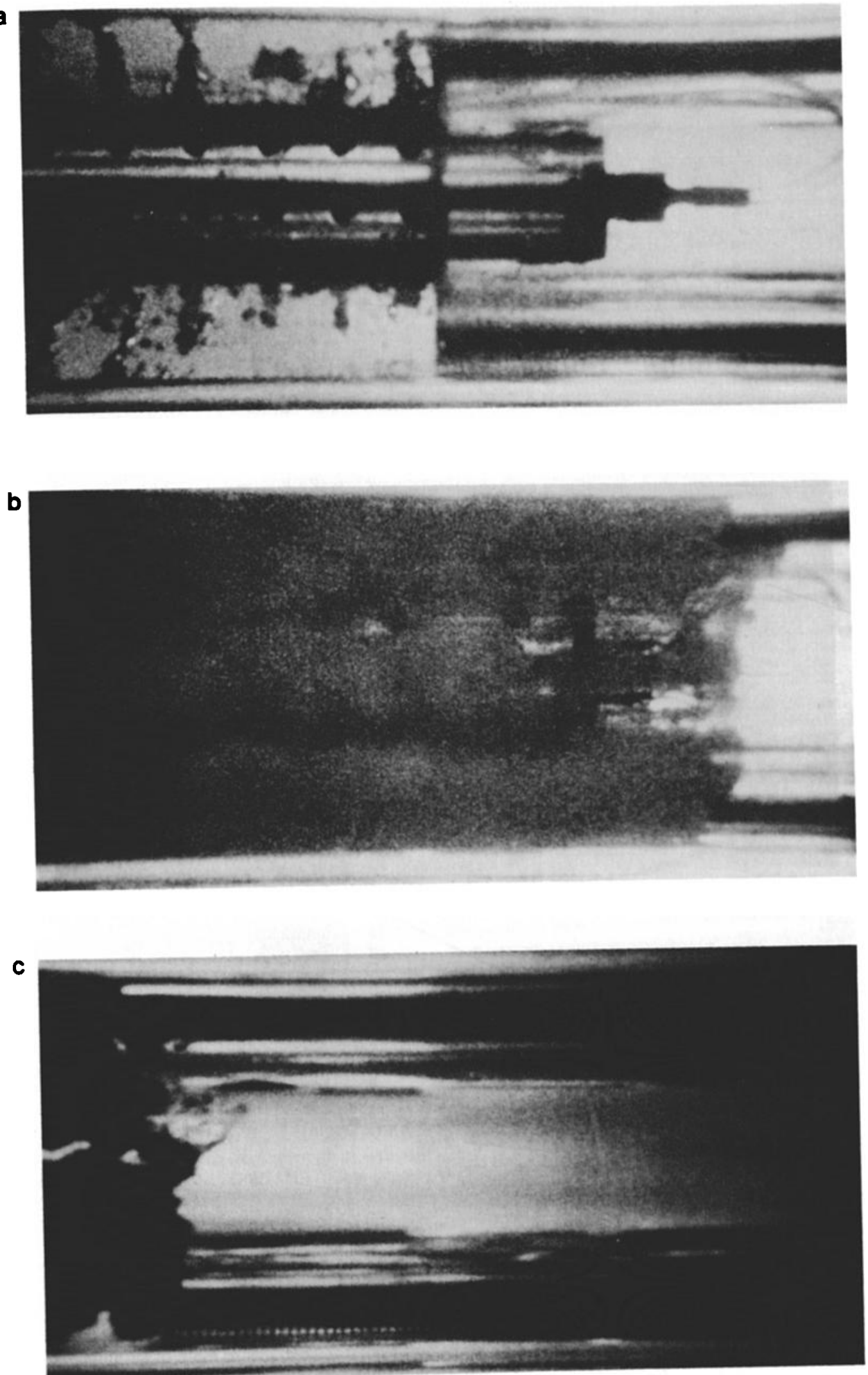

Figure 4. Views of a typical explosively expanding foam flow produced hy the injection of $6 \mathrm{M} \mathrm{K}_{2} \mathrm{CO}_{3}$ into 6 $M \mathrm{HCl}$. Each view shows about $9 \mathrm{~cm}$ of the shock tube. The initial height of the HCl in the test cell for this series was $h_{o}=10 \mathrm{~cm}$. In the following, the height of the flow front ahove $h_{0}$ is called $\Delta h=h-h_{o}$. (a) Injection event(l $=32 \mathrm{~ms} ; \Delta h=0 \mathrm{~cm}$ ). (b) Two-phase flow expanding in the amnular region betweell the injector and test cell walls $(t=41 \mathrm{~ms} ; \Delta h=3.5 \mathrm{~cm})$. (c) Converged two-phase flow which has detached from the tulie walls $(t=51 \mathrm{~ms} ; \Delta h=$ $7.3 \mathrm{~cm}$ ). (d) Onset of flow front fragmentution $(t=54 \mathrm{~ms} ; \Delta h=9.9 \mathrm{~cm})$. (c) Fragmentation region $(t=55.5 \mathrm{~ms}$; $\Delta h=12.3 \mathrm{~cm}$ ). (f) Fragmentation region $(l=78 \mathrm{~ms} ; \Delta /=41.5 \mathrm{~cm})$. 

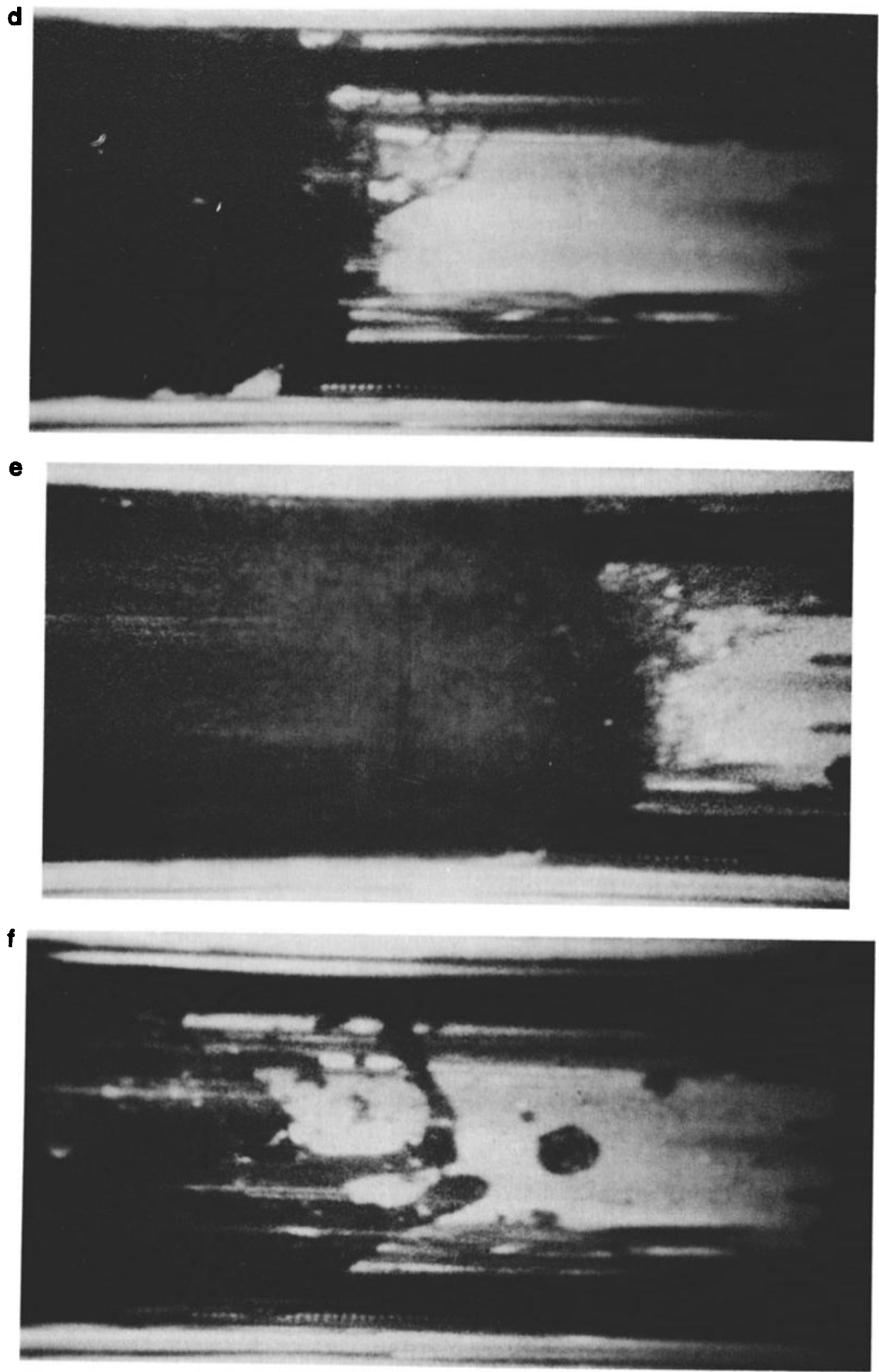

Figure 4. (continued)

surface was observed to rise by $1.3 \mathrm{~mm}$ in response to the increased volume of fluid on injection but no other motion was observed.

An example of a typical experiment is illustrated by the six photographs shown in Figure 4. The photographs were printed from 16-mm high-speed ciné film, which was exposed at a framing rate of 5000 frames per second (fps); the print quality is reduced because of the resulting large grain size, but the key features of the flows are reproduced. In the experimental ron shown in Figure 4, $6 \mathrm{M} \mathrm{K}_{2} \mathrm{CO}_{3}$ was injected into $6 \mathrm{M} \mathrm{IICl}$. In our experiments, the high degree of vesiculation causes the main body of the flow to be essentially opaque during much of an 
experiment. In this section we describe the processes occuming during injection and at the head of the flow where clear features can be identified.

Figure 4a shows the injection of the $\mathrm{K}_{2} \mathrm{CO}_{3}$ into the IICl. When the injector is in the closed position. the seal between the two reactants is not perfect. Small amounts of leakage can occur lesding to the formation of a few individual bubloles in the test cell near the injector prior to an experiment. The time $t=0$ is taken as the time when the internal cylinder is rotated to open the injector holes and is therefore the time when the reactants are first properly in contact. This occurs $50 \mathrm{~ms}$ after the camera has reached the desired framing rate. The plunger, which performs the injection stroke, is activated $t=20 \mathrm{~ms}$ later. Figure $4 \mathrm{a}$ was taken at $t=32 \mathrm{~ms}$ and shows clearly the formation of turbulent jets from the injector holes. The jets are well developed at the base but are only in the initial stages of development $3 \mathrm{~cm}$ up the injector. This is because the injection process takes $14 \mathrm{~ms}$ from the first appearance of the jets at the base to full development of turbulent jets at the top of the injector. Bublsle nucleation is seen to commence within the turbulent jets after a delay of a few milliseconds. Thus bubble nucleation is clearly subject to hoth temporal inhomogeneity, due to the variation of injection time along the injector, and spatial inhomogeneity, due to nucleation being restricted to the region of the jets.

Figure $4 \mathrm{~b}$ shows the flow front at $t=41 \mathrm{~ms}$ and a height $\Delta h=$ $3.5 \mathrm{~cm}$ above the initial position of the liquid-air interface. The initial stages of the motion of the flow are controlled by flow around the injector. The flow propagates in the annular region defined by the test cell walls and the edge of the injector and remains in this region after flowing past the injector for some distance. Mixing across the test cell diameter occurs when the flow front reaches a height of approximately $\Delta / t=8 \mathrm{~cm}$. It is not possible to determine exactly the point of convergence hecause the flows are essentially opaque due to the extremely finely bubbled texture of these foams. Individual bubbles caunot he resolved in the initial stages of the flow.

Figure $4 \mathrm{c}$ shows the flow front at $t=51 \mathrm{~ms}$ and $\Delta / 7=7.3 \mathrm{~cm}$. The initially annular flow has converged at the tube center to form a plug flow regime. Near the flow front, the foam is detached from the tube walls. The height where the flows furst become detached from the tube walls depends on how violent the expansion is; the fastest flows detach as much as $7 \mathrm{~cm}$ lower down the tube than the slowest. The void space introduced by the detachment of the flow from the walls is a small fruction of the total volume of the flow (at most 15\%). The flow front in Figure $4 c$ is in the initial stages of fragmentation with foam ligaments (about $1 \mathrm{~mm}$ in length) extending ahead of the propagating now giving the flow front a roughened appearance. These ligaments first appear at the point of convergence and are thought to arise from the collision of the foan streams.

Figures $4 \mathrm{~d}(t=54 \mathrm{~ms}, \Delta h=9.9 \mathrm{~cm})$ and $4 \mathrm{e}(t=55.5 \mathrm{~ms}, \Delta h=$ $12.3 \mathrm{~cm}$ ) show the fragmentation of the foam at the flow front. The foam ligaments expand with the flow to a length of typically $3 \mathrm{~cm}$ before fragmentation occurs. Initially, the fragmentation products at the flow head are shorter ligaments of approximately $0.5 \mathrm{~cm}$ in length which then form droplets of liquid and foam with diameters of a few millimeters. The visible fragmentation region extends over a height range of approximately $5 \mathrm{~cm}$.

Figure $4 \mathrm{f}$ shows the flow front at $t=78 \mathrm{~ms}$ and $\Delta h=41.5 \mathrm{~cm}$. The flow front is now fully fragmented and a wide range of fragment sizes is evident. In this experimental run we observed foam ligaments extending up to $5 \mathrm{~cm}$ in length prior to breaking down into foam globules (diameters of order $1 \mathrm{~cm}$ ) and liquid droplets (diameters of order $0.1 \mathrm{~cm}$ ). No clear fragmentation front is visible. Fragmentation occurs over a diffuse region which increased in length with time. Accurate determination of the location of the flow front is made difficult by the fragments moving ahead of the main body of the flow. The highest point at which the flow appears as fully opaque is taken to be the llow front. As fragmentation occurs in a region detached from the test cell walls, wall shear stress cannot limit the extension of the foum ligaments. Ongoing mixing of the two reactants leads to spatially and temporally nonuniform bubble nucleation and growth. The result is the highly heterogeneous flow and fragunentation seen here.

\section{Position of the Flow Front With Time}

Figure $\mathbf{5}$ shows the position of the flow front with time for the six series specified in Table 1 . The data for each experiment were digitized by hand from the films. The exact time of injection for each run was not always known as the injector was only in view for one run in a given series. A smooth composite plot was obtained by adjusting the zero of time for euch run. This procedure was considered legitimate since an analysis of the
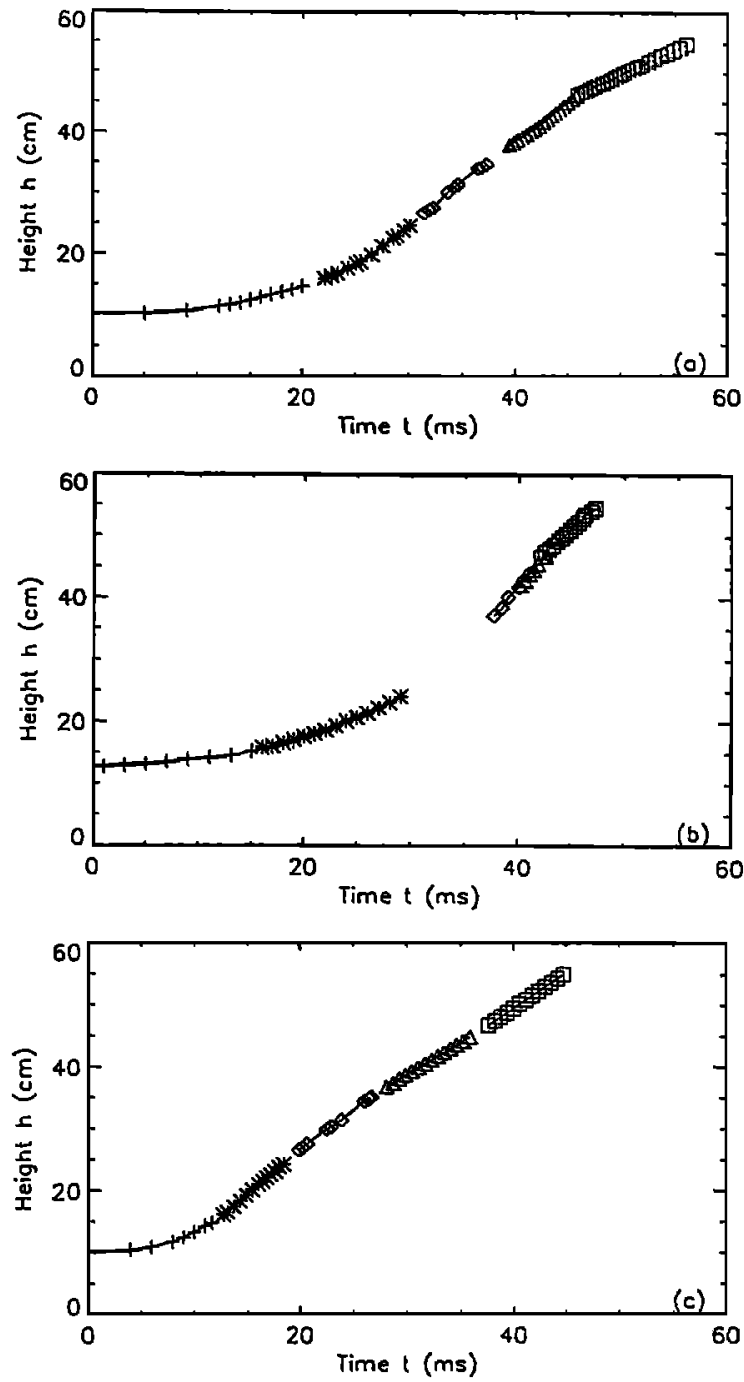

Figure 5. Position of the flow front versus time for the six series specified in Table 1 . The height plotted here is the height $h$ above the base plate. The different symbols denote clata from different views of the test cell. Heights are accurate to $\pm 1 \mathrm{~mm}$ and times $t o$ $0.2 \mathrm{~ms}$ (1 frame). Thus the error bars are about the size of the symbols and so are not shown. (a) Series 1: $6 \mathrm{M} \mathrm{K}_{2} \mathrm{CO}_{3} \rightarrow 6 \mathrm{M}$ HCl. (b) Series 2: $6 \mathrm{M} \mathrm{K}_{2} \mathrm{CO}_{3} \rightarrow 6 \mathrm{M}$ IICl. (c) Series 3: $6 \mathrm{M}$ $\mathrm{K}_{2} \mathrm{CO}_{3} \rightarrow 9 \mathrm{M} \mathrm{HCl}$. (d) Series 4: $6 \mathrm{M} \mathrm{K}_{2} \mathrm{CO}_{3} \rightarrow 12 \mathrm{M} \mathrm{IICl}$. (e) Series 5: $6 \mathrm{M} \mathrm{K}_{2} \mathrm{CO}_{3} \rightarrow 12 \mathrm{M} \mathrm{HCl}$ (f) Series 6: $4.5 \mathrm{M} \mathrm{K}_{2} \mathrm{CO}_{3} \rightarrow$ $12 \mathrm{M} \mathrm{HCl}$. 



Figure 5. (continued)

pressure traces from the runs suggested that conditions are highly repeatable in most experiments (see Pressure Traces). However, an exception is evident in the composite plot of serics 5 (Figure 5e). The first two runs of this series do not join smoothly. This suggests that conditions were not strictly repeatable during these particular runs resulting in a difference in the acceleration experienced by the flow. As series 5 is one of the two series for which we have no pressure traces, it is not possible to make a clear statement about exactly how the conditions varied. nor is it possible to say which of the first two runs deviates most from the others in the series.

Figure 6 shows the data from Figure 5 replotted in log-log form. The series are grouped in pairs according to their theoretical supersaturation. All graphs have pronounced linear sections during the initial stages of the flow with slopes of 2.36 to 3.26. This means that the acceleration over thesc regions is increasing with time; a slope of 2 implies constant accelcration and a slope of 3 corresponds to a linearly increasing accelerution.

The motion of the flow front is principally influenced by the $\mathrm{CO}_{2}$ supersaturation. This is supported by the comparison of series 6 (injection of $4.5 \mathrm{M} \mathrm{K}_{2} \mathrm{CO}_{3}$ into $12 \mathrm{M}$ IICl) and scrics 3 (injection of $6 \mathrm{M} \mathrm{K}_{2} \mathrm{CO}_{3}$ into $9 \mathrm{M} \mathrm{HCl}$ ) which show similar fluw front evolution (Figure $6 \mathrm{~b}$ ). These flows have different potential $\mathrm{CO}_{2}$ yields but the same theoretical $\mathrm{CO}_{2}$ supersaturation.

\section{Velocity and Acceleration}

The velocity of the flow front as a function of time and height is shown in Figure 7. These plots were generated by drawing smooth curve, fitted by eye, through the raw height-versus-tine
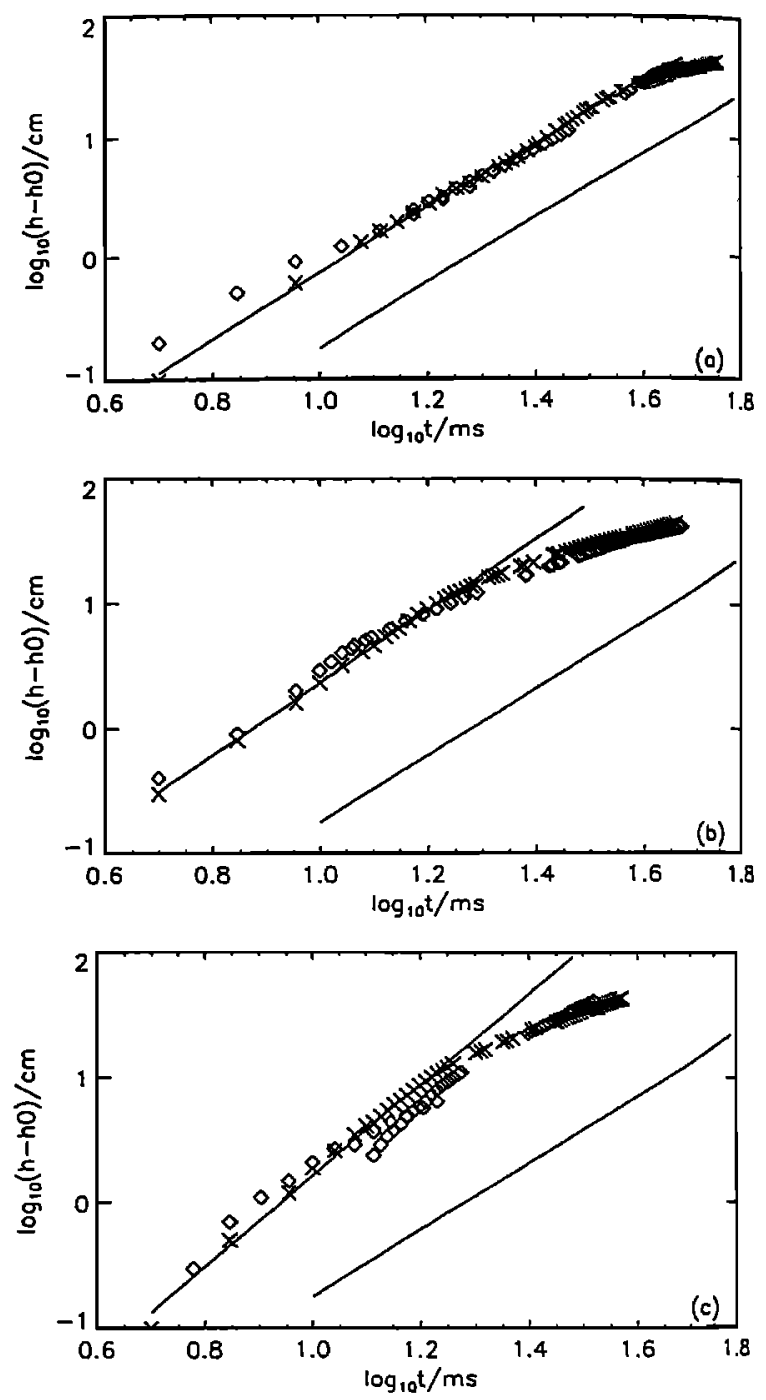

Figure 6. Logarithmic plots of the position of the flow frod versus time for the six series specified in Table 1 . In each graph the two composite series with the same theoretical supersaturation pressure are displayed together. A least squares fit of the initial linear part of the data was made to the function $h-h_{0}=A$. where $h_{o}$ is the initial height of the liquid in the test cell, with the following results: (a) Theoretical supersaturation: $S=303$, where crosses are series 1: $6 \mathrm{M} \mathrm{K}_{2} \mathrm{CO}_{3} \rightarrow 6 \mathrm{M} \mathrm{HCl} . A=1.49 \times 10^{-3}, b=$ $2.69, h_{o}=10.1 \mathrm{~cm}$ (fit shown); diamonds are series $2: 6 \mathrm{M}$ $\mathrm{K}_{2} \mathrm{CO}_{3} \rightarrow 6 \mathrm{M} \mathrm{HCl} . A=2.10 \times 10^{-3}, b=2.56, h_{o}=13.1 \mathrm{~cm}$. (b) Theoretical supersaturation; $S=390$, where crosses are series 3 : $6 \mathrm{M} \mathrm{K}_{2} \mathrm{CO}_{3} \rightarrow 9 \mathrm{M} \mathrm{HCl} . A=1.20 \times 10^{-2}, b=2.44, h_{o}=10.0 \mathrm{~cm}$ (fit shown); diamonds are series 6: $4.5 \mathrm{M} \mathrm{K}_{2} \mathrm{CO}_{3} \rightarrow 12 \mathrm{MHCl.d}$ $=1.69 \times 10^{-2}, b=2.36, h_{o}=10.1 \mathrm{~cm}$. (c) Theoretical supersaturation; $S=455$, where crosses are series 4: $6 \mathrm{M} \mathrm{K}_{2} \mathrm{CO}_{3}$ $\rightarrow 12 M$ HCl. $A=1.07 \times 10^{-3}, b=3.26, h_{O}=10.1 \mathrm{~cm}$ (fit showat) diamonds are series 5: $6 \mathrm{M} \mathrm{K}_{2} \mathrm{CO}_{3} \rightarrow 12 \mathrm{M} \mathrm{HCl} . A=3.80 \times 10^{5}$, $b=2.68, h_{o}=12.9 \mathrm{~cm}$. A line of slope $=8 / 3=2.67$ is also shaw in each graph for comparison. 

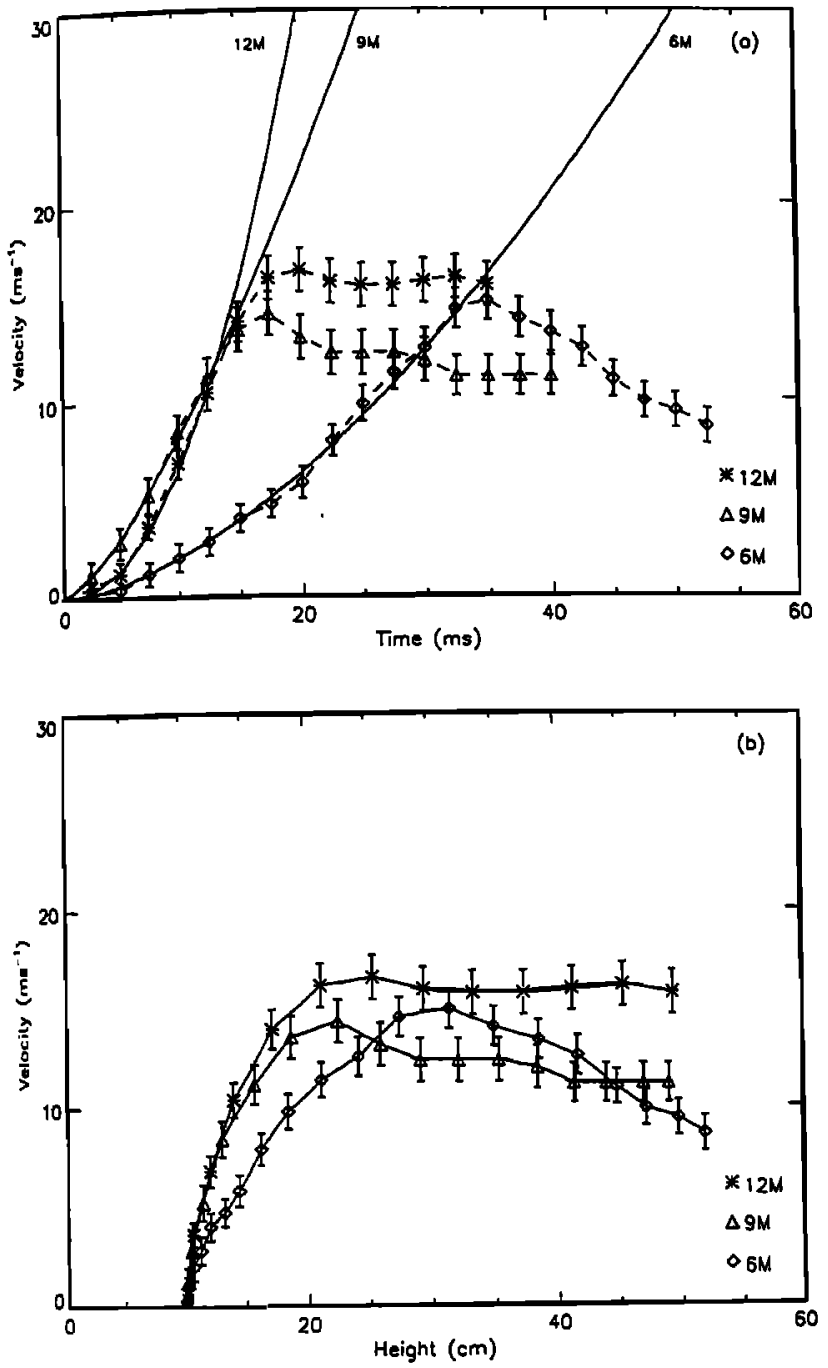

Figure 7. Velocity of the flow front as a function of (a) time and (b) beight for series 1 ( $6 \mathrm{M} \mathrm{K}_{2} \mathrm{CO}_{3} \rightarrow 6 \mathrm{M} \mathrm{HCl}$ ) (diamonds), series $3\left(6 \mathrm{M} \mathrm{K}_{2} \mathrm{CO}_{3} \rightarrow 9 \mathrm{M} \mathrm{HCl}\right.$ ) (triangles), and series 4 (6M $\mathrm{K}_{2} \mathrm{CO}_{3} \rightarrow 12 \mathrm{M} \mathrm{HCl}$ ) (crosses). The solid lines in Figure $7 \mathrm{a}$ are derived from the best fit lines of Figure 6 .

datr for series 1, 3, and 4. Heights were measured at 2.5-ms time intervals along the fitted curve, and average velocities over 5-Ins time intervals were then calculated using the measured heights and times and assigned to the midpoint. The error bars on the velocity values are derived from the uncertainties in the time intervals and height differences. There is a constant absolute uncertainty on the measurement of time intervals of $\pm 0.14 \mathrm{~ms}$ which translates into a constant percentage error of $\pm 3 \%$ because the time interval is a fixed $5 \mathrm{~ms}$. The uncertainty in the height difference is the sum of the uncertainty due to the measurement procedure and the variance of the fitted curve. The first part of the velocity-versus-time curves is in good agreement with the curves of the first derivatives of the least squares fits produced for Figure 6.

The maximum velocities reached are the same to within the tror for all the series, namely, about $15 \mathrm{~m} \mathrm{~s}^{-1}$. The figure shows that higher supersaturation implies greater acceleration; for example, taking the error bars into account, a velocity of $15 \mathrm{~m} \mathrm{~s}^{-1}$ is reached over a distance of $17.1 \mathrm{~cm}(12 M, S=455) .20 .7 \mathrm{~cm}(9$ $M, S=390), 31.5 \mathrm{~cm}(6 M, S=303)$. The initial acceleration is similar for the first two cases ( $12 M, 9 M)$ but diverges markedly after the first $4 \mathrm{~cm}$ of motion. The subsequent deceleration is more pronounced for lower supersaturation.

An estimate for the maximum acceleration experienced by these flows was obtained by plotting the velocity-versus-time data on a $\log -\log$ plot. The initial part of each of these curves is linear and so the power law describing the data could be determined using standard regression techniques. The scatter of the points in fact gives a range of possible power laws and so the first derivatives of these curves gives the maximum acceleration and the uncertainty in this value. The maximum acceleration tends to increase with increasing supersaturation from $75 \pm 15 \mathrm{~g}$ at $S=$ 303 to $125 \pm 10 \mathrm{~g}$ at $S=390$ and then to nearly $180 \pm 40 \mathrm{~g}$ at $S=$ 455.

Figure 8 shows the relationship between the theoretical supersaturation and the maximum acceleration for the three experimental conditions. This figure suggests that there is a correlation between the observed acceleration of the flow front and the initial gas supersaturation. The data are well fitted by linear $(R=0.994)$ and second order polynomial $(R=1)$ fits which do not pass through the origin. These fits imply that there is an initial value of supersaturation which must be attained hefore any flow acceleration results. This result is intuitively correct; taking the top off a bottle of carhonated water, which creates a $\mathrm{COO}_{2}$ supersaturation, does not always result in an accelerating flow.

\section{Pressure Traces}

Figure 9 shows output from the pressure transducer PT1 from five runs for each of the experimental conditions. The traces suggest that there is a general form of the pressure trace from this transducer which measures the momentum flux transferred to the base of the test cell by the expanding flow. The pressure traces in Figure 9 are bighly repeatable for each of the experimentul conditions and justify the procedure of creating composite plots from several runs of the same experiment.

In order to distinguish between pressures produced by the evolving gases during the chemical reaction and pressures measured due to the injection process, dummy runs were performed in which air was injected into air (i.e.. the solenoid valves and pistons were operated with an emply test cell) and water was injected into water. The PTl pressure trike for the air

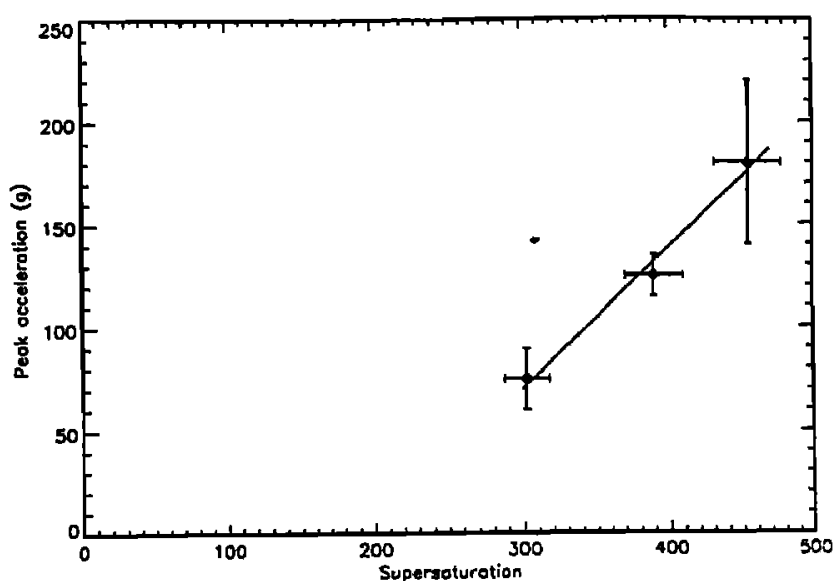

Figure 8. Peak acceleration as a function of the calculated supersaturation for the injection of $6 \mathrm{M}, 9 \mathrm{M}$ and $12 \mathrm{M} \mathrm{K}_{2} \mathrm{CO}_{3}$ into $6 \mathrm{M} \mathrm{HCl}$. The error bars indicate the uncertainty in the peak acceleration value due to the method of calculation, and in the supersaturation due to variation in solution concentration (ste Experimental Results section). 

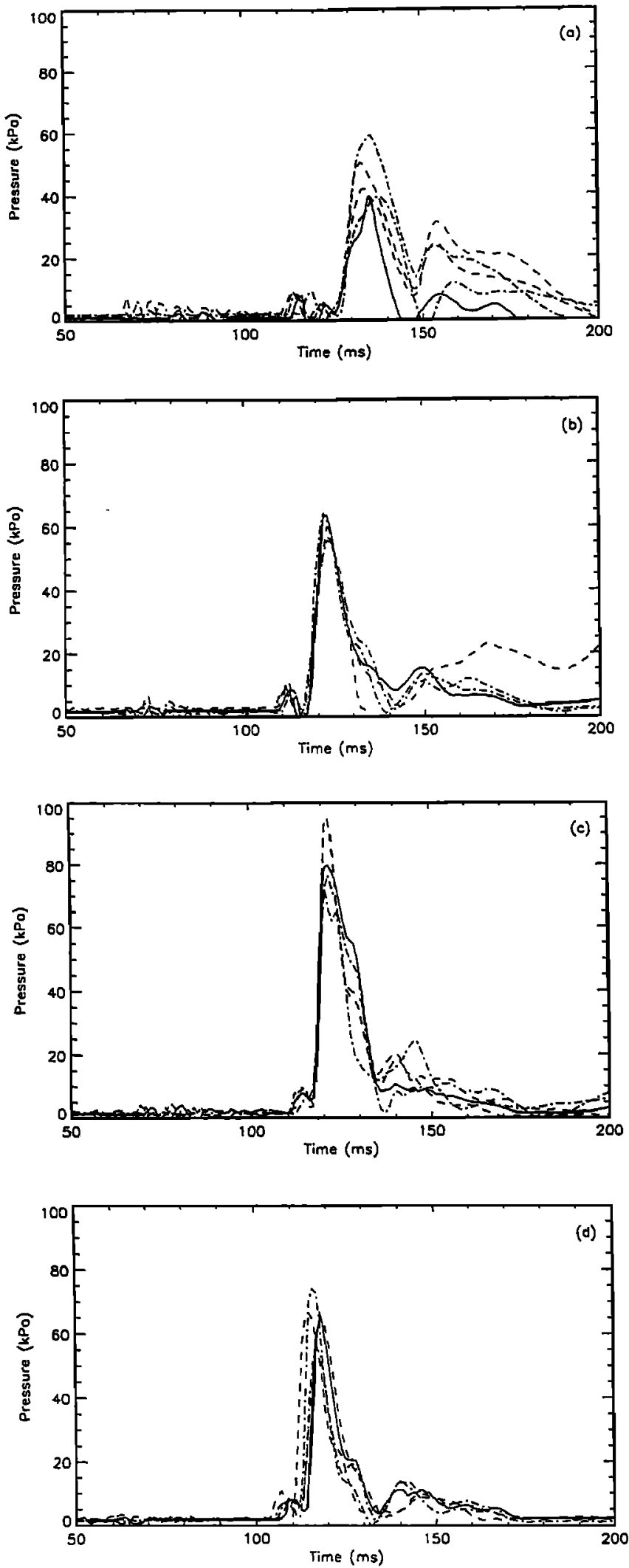

Figure 9. Pressure traces. Each plot shows the pressure recorded as a function of time during five runs under the same experimental conditions. To facilitate comparisons, the zero of the time axis for each pressure trace has been modified so that the five graphs on each plot are superimposed as closely as possible:

(a) $6 \mathrm{M} \mathrm{K}_{2} \mathrm{CO}_{3} \rightarrow 6 \mathrm{M} \mathrm{HCl}$, (b) $6 \mathrm{M} \mathrm{K}_{2} \mathrm{CO}_{3} \rightarrow 9 \mathrm{M} \mathrm{HCl}$, (c) $6 M$ $\mathrm{K}_{2} \mathrm{CO}_{3} \rightarrow 12 \mathrm{M} \mathrm{HCl}$, and (d) $4.5 \mathrm{M} \mathrm{K}_{2} \mathrm{CO}_{3} \rightarrow 12 \mathrm{M} \mathrm{HCl}$.

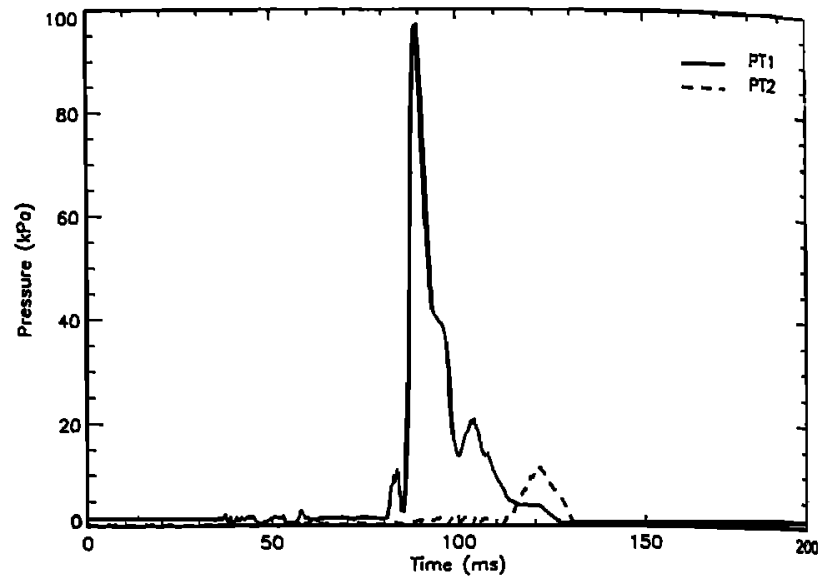

Figure 10. An example of the pressure signal for the injection of $6 \mathrm{M} \mathrm{K}_{2} \mathrm{CO}_{3}$ into $6 \mathrm{M} \mathrm{HCl}$.

into air dummy run showed small fluctuations of the order of a few kilopascals due to mechanical vibrations. The trace for the water into water dummy run also showed these small fluctuations followed by a pressure pulse with a peak pressure of ahout $10 \mathrm{kPa}$ on injection of the water into the annular region.

The general features of a typical PT1 pressure signal are illustrated in Figure 10. The trace can be sectioned into several parts: the injection event, the peak pressure and the decay of pest pressure. The operation of the injector commences in this example at $t=50 \mathrm{~ms}$. The small fluctuations of order $3-4 \mathrm{kPa}$ between $t=50 \mathrm{~ms}$ and $t=80 \mathrm{~ms}$ are attributed to mechanical vibrations generated during the injection process (compare with air into air dummy run described above). The first prominent peak of $12 \mathrm{kPa}$ at $t=83 \mathrm{~ms}$ is also due to the injection process and represents the pressure exerted by the turbulent flow of $\mathrm{K}_{2} \mathrm{CO}_{3}$ into the test cell (compare with water into water dumny run described above). Over the following 3-4 ms, there is a nucleation delay followed by a rapid rise in the pressure to 97 $\mathrm{kPa}$, the second peak. This is the most pronounced peak of the pressure profile and is due to the initial explosive event. The pressure measured gives a direct measure of the thrust experienced by the flow. There follows a rapid decay to alood 15 $\mathrm{kPa}$ over $5 \mathrm{~ms}$ followed by a more gradual decay to ambient over a further $30 \mathrm{~ms}$.

The pressure trace measured at the test cell top P12 is also shown in Figure 10. This trace suggests compression of the air initially in the test cell above the reactants as the flow expands producing the observed increase in pressure to about $10 \mathrm{kPu}$ at 30 ms after the injection event. The sensitivity of the transelucer is not sufficient to provide more detail of the pressure conditions a the top of the test cell.

\section{Discussion}

\section{Gas Evolution and Foam Expansion}

The results show that our apparatus produces violently expanding two-phase flows with a high degree of reproducibility. The flows experience accelerations up to $180 \mathrm{~g}$ and velocities up to $15 \mathrm{~m} \mathrm{~s}^{-1}$. The rate of generation of $\mathrm{CO}_{2}$ and therefore flow expansion is potentially limited by four main factors: chemical reaction kinetics, fluid mechanical mixing. bubble nucleation kinetics, and diffusive bubble growth. In this section we evalust the contribution of these factors to gas evolution.

We first discuss the influence of the chemical reaction physical mixing. The chemical reaction used to produce our expanding two-phase flows is the decomposition of $\mathrm{K}_{2} \mathrm{CO}_{3}$ $\mathrm{CO}_{2}$ : 


$$
\mathrm{K}_{2} \mathrm{CO}_{3}+2 \mathrm{HCl}=2 \mathrm{KCl}+\mathrm{CO}_{2}+\mathrm{H}_{2} \mathrm{O} .
$$

The rapid forward reaction in the decomposition of carbonate can occur via the following reaction [Banford and Tripper, 1969]

$$
\mathrm{H}^{+}+\mathrm{HCO}_{3}^{-}=\mathrm{H}_{2} \mathrm{CO}_{3}=\mathrm{CO}_{2}+\mathrm{H}_{2} \mathrm{O}
$$

The first stage of this reaction is second order in $\mathrm{HCO}_{3}$ consumption with a forward reaction rate constant of $k=4.7 \times 10^{10}$ $\mathrm{L} \mathrm{mol}^{-1} \mathrm{~s}^{-1}$ [Bamford and Tripper, 1969], which for practical purposes is instantaneous. The second stage of the reaction is first order in $\mathrm{H}_{2} \mathrm{CO}_{3}$ consumption and has a rate constant of $k=1.5 \mathrm{~s}^{-1}$ [Bamford and Tripper, 1969]. To analyze the chemical reactions in our experiments, we model the test cell as a stirred-tank reactor. If we assume standard dilute reaction kinetics, then for this first-order reaction we have

$$
\dot{N}_{\mathrm{H}_{2} \mathrm{CO}_{3}}=-k N_{\mathrm{H}_{2}} \mathrm{CO}_{3}
$$

where $\mathrm{N}_{2} \mathrm{CO}_{3}$ is the number of moles of $\mathrm{HI}_{2} \mathrm{CO}_{3}$ in the reactor. Hence

$$
N_{\mathrm{H}_{2} \mathrm{CO}_{3}}=N_{o} e^{-k t}
$$

where $\mathrm{N}_{0}$ is the initial number of moles of $\mathrm{H}_{2} \mathrm{CO}_{3}$. We have here furthermore assumed that the reactants are homogeneously pre mixed in which case $N_{0}$ is also the total number of moles of $\mathrm{H}_{2} \mathrm{CO}_{3}$ available in the system for conversion into $\mathrm{CO}_{2}$. The time taken for the concentration of $\mathrm{H}_{2} \mathrm{CO}_{3}$ to fall to 1/eth of its initial concentration is $t=66 \mathrm{~ms}$. The formation of $\mathrm{CO}_{2}$ is thus the rate limiting step in the chemical reaction. Now, by (2)

$$
\dot{N}_{\mathrm{CO}_{2}}=k N_{\mathrm{H}_{2} \mathrm{CO}_{3}}
$$

and so

$$
N_{\mathrm{CO}_{2}}=N_{o}\left(1-e^{-k t}\right)
$$

In Figure 11 we compare the increase of $\mathrm{C.O}_{2}$ volume with time for our experiments, with the $\mathrm{CO}_{2}$ production predicted on the basis of the above dilute reaction kinetics and the assumption that the reactants are homogeneously pre mixed. The graph elcarly shows that the evolution of $\mathrm{CO}_{2}$ in our experiments is different

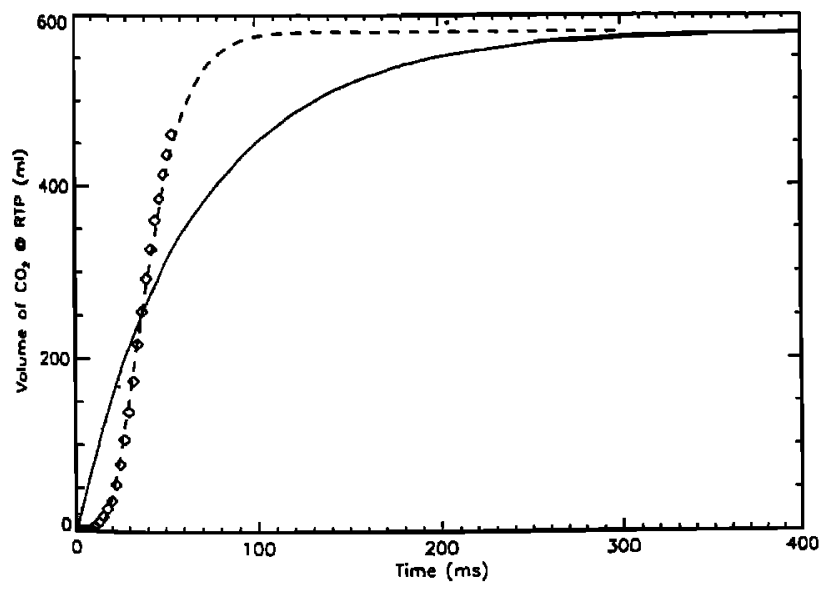

Figure 11, Evolution of $\mathrm{CO}_{2}$ volume with time. The points show the observed gas evolution for $6 \mathrm{MK}_{2} \mathrm{CO}_{3}$ injected into $6 \mathrm{M} \mathrm{HCl}$. The solid curve shows the evolution calculated using the simple dilute reaction kinetics described in the text, the dashed curve is the model fit to the observed data (see Discussion section). from that predicted by the dilute reaction kinetics; for small times the rate of evolution is much less than predicted; however, for times $t>30 \mathrm{~ms}$ the observed evolution rate greatly exceeds prediction. The dilute kinetic $\mathrm{CO}_{2}$ production curve asymptotically approaches a maximum yicld of $0.58 \mathrm{~L}$, assuning room temperature and pressure (RTP) conditions. The experimental $\mathrm{CO}_{2}$ volume can only the determined for the initial $50 \mathrm{~ms}$ of the experimental run, as subsequently the expanding flow is not observable. The experimental curve must also approach the maximum $\mathrm{CO}_{2}$ yield value of $0.58 \mathrm{~L}$. The gradient of the experimental curve reduces from its maximum value as time increases. Thus we could reasonably expect that measurements taken at later times would show an increasingly rapid drop in gas exsolution as the reaction reaches completion and that the experimental curve might approach the dilute kinetic curve for large times.

The behavior observed at small times is functionally different from that predicted for dilute solutions. und the rate of gas evolution measured is several orders of magnitude less. Explanations for the discrepancy between the curves are the consequence of physical mixing and the kinetics of bubble nucleation and growth. The reactants are initially not well mixed and so the reaction is slower to get started than predicted by the dilute reaction kinetics which assume a well mixed situation. For times exceeding about $40 \mathrm{~ms}$, the observed volumes of $\mathrm{CO}_{2}$ are in excess of those predicted by the theory. This suggests that the reaction kinetics for these highly concentrated solutions must be significantly faster than suggested by the dilute reaction kinctics and that therefore the gas evolution is limited primarily by fluid mechanical mixing and the kinetics of hublic formation and growth.

We now consider mixing. In our experiments gas evolution promotes mixing which in turn could lead to further gas evolution. The positive feedback effect in the flows leads to the accelerated gas evolution rate observed. This can be quantified as follows. In order to account for the effects of mixing. we represent the left-hand side of (3) as the sum of two terms.

$$
\dot{N}_{\mathrm{H}_{2} \mathrm{CO}_{3}}=\dot{N}_{R}+\dot{N}_{M}
$$

where $\dot{N}_{R}=-k N_{\mathrm{H}_{2} \mathrm{CO}_{3}}$ and $\dot{N}_{M}$ is determined from a mixing model. One description of the mixing can be derived by making a conventional mixing hypothesis [Turner, 1973], namely, that IICl and $\mathrm{K}_{2} \mathrm{CO}_{3}$ are brought together at a rate proportional to the volume flux (velocity times the cell cross-sectional areu). The liberation rate of $\mathrm{CO}_{2}$ therefore has a proportionality constant $\beta$ Then, from (2), a similar analysis to (3) to (6) leads to the result

$$
N_{\mathrm{CO}_{2}}=\frac{N_{i}}{1-\beta}\left(1-e^{-k(1-\beta) t}\right)
$$

where $N_{i}$ is the initial number of moles of $\mathrm{H}_{2} \mathrm{CO}_{3}$ and $\mathrm{N}_{i} /(1-$ $\beta)=N_{0}$ the total number of moles of $\mathrm{H}_{2} \mathrm{CO}_{3}$ available in the system. The duration of the reaction is prolonged over that of (6). but otherwise the mixing hypothesis does not change the fundamental nature of the chemical reaction and therefore cannot by itself reproduce the observed gas evolution.

We now consider diffusive bubble growth as a rate-limiling process. The volume expansion of the flows has been shown to follow a power law relationship with the height $\Delta h \alpha t^{2.5}$ to $t^{3}$ (volume expansion $\alpha \Delta h$ as the test cell is cylindrical). This result can be compared with that expected for diffusive growth of bubbles after a discrete nucleation event and with experimental results of expansion of aqueous solutions containing dissolved $\mathrm{CO}_{2}$ under pressure and subjected to a sudden decompression [Mader et al., 1994]. Diffusive growth of spherical hulbbles in an infinite, stationary fluid should follow the parabolic law $R \propto, t^{0.5}$. 
where $R$ is the radius of the bubbles [Scriven 1959; Sparks et al., 1994]. Thus the volume expansion and hence $\Delta / 2$ in our experiments would increase as $t^{15}$. The aqueous experiments with dissolved $\mathrm{CO}_{2}$ [Mader et al., 1994] showed a discrete nucleation event following decompression, but these flows expanded at constant acceleration ( $\Delta h \alpha t^{2}$ ). The behavior in those experiments can be interpreted as a consequence of bubble advection [Mader et al., 1994] which gives this power law if the bubble grows by diffusion whilst rising at a constant velocity through the surrounding liquid [van Wijngaarden. 1967].

The higher expansion rates observed in these experiments can be attributed to a number of factors. The models discussed above assume that there is only one nucleation event. assume that the gas is initially uniformly dissolved throughout the fluid (i.e.. the chemical reaction and mixing processes are very fast) and assume that the expanding bubbles have identical growh histories. In our experiments the mixing of the reactants must result in progressive nucleation of bubbles leading to increased gas production with time in the early stages of the flows. The flows are likely to be bighly heterogeneous as a consequence of incomplete mixing. They are also turbulent and this might enhance the advective contribution to growth. Furthermore, it is probable that the bubbles are not spherical but hecome highly deformed in the rapidly accelerating flow field. This would have the effect of increasing the surface area to volume ratio with time, hence promoting diffusion into the bubble [Sparks et al. 1994].

Our analysis of end-member models indicates that no single process completely dominates the gas evolution and expansion. The dilute chemical reaction kinetics and simple physical mixing cannot produce the observed gas evolution. Similarly. diffusionlimited bubble growth cannot generate the olsserved rates. Expansions are strongly correlated with the supersalurution in our experiments. Also bubble nucleation rates increase strongly with supersaturation [Swanger and Rhines, 1972] and thus we expect that void formation increases with flow expansion rate. Therefore there is a strong feedback between chemical generation of dissolved $\mathrm{CO}_{2}$ due to progressive mixing of reactants and bubble nucleation rates.

In order to produce a rational description of the expansion it is necessary to invoke strong nonlinearities in the system. This process can be modeled as a stirred-tank reactor into which reactants are continuously and nonlinearly blended. We empirically model nonlinear mixing by adopting a mixing law in accord with the observed power law time clependence of fluid velocity, moderated by a late-time exponential decay.

$$
\dot{N}_{M}=C t^{2} e^{-x a}
$$

where $C$ and $\kappa$ are empirical constants. We solve (7) with (3) and (9), subject to the condition that there is no $\mathrm{H}_{2} \mathrm{CO}_{3}$ present initially:

$$
N_{\mathrm{H}_{2} \mathrm{CO}_{3}}=\frac{C t^{3}}{3} e^{-10} .
$$

From (5), integrating (10) gives the result

$$
\begin{aligned}
& N_{\mathrm{CO}_{2}}=\frac{\kappa C}{3} \int_{0}^{t} t^{3} e^{-\kappa \pi} d t \\
& N_{\mathrm{CO}_{2}}=\frac{2 C}{\kappa^{3}}\left[1-\left(1+\kappa t+\frac{\kappa^{2} t^{2}}{2}+\frac{\kappa^{3} t^{3}}{6}\right) e^{-\kappa]}\right] .
\end{aligned}
$$

The result of fitting (11), multiplied by the molar volume of $\mathrm{CO}_{2}$ at RTP, to the experimental data is shown in Figure 11 by the dashed line. The empirical values used are $C=1.46 \times 10^{4} \mathrm{~mol} \mathrm{~s}-3$ and $k=107 \mathrm{~s}^{-1}$. In addition, in the plot the start of (11) has been arbitrarily delayed by $6.5 \mathrm{~ms}$ in order to improve the fit.
The model represents the observed behavior satisfactorily. Presumably, a better fit could be achieved for each run hy assuming a noninteger power of $t$ and evaluating its value by a least squares fit with a numerical integration of (10). However, the simple argument presented here is sufficient to make the point that the mechanism of mixing and the enhancement of gas evolution by rapid expansion are crucial to the explosive behavior. It is significant that the fit does not admit a finite value for the amount of $\mathrm{H}_{2} \mathrm{CO}_{3}$ present at the outset which is consistent with the fact that mixing is initiated between two separated reactants.

\section{Fragmentation of Expanding Foam Flows}

If the rate of deformation of the expanding flow exceeds the relaxation rate of the fluid then fragmentation occurs. We can distinguish between ductile fragmentation (used in the generation of industrial and agricultural sprays) which results from the generation and growth of fluid instabilitics, and britle fragmentation, where the extensional strain rates are such that the liquid crosses the glass transition.

In the process of ductile fragmentation, the liquid flow is subjected to an initial perturbation which results in the distortion of the flow into liquid ligaments. Liquid surface tension controls the breakup of ligaments into droplets or globules which subsequently disintegrate into smaller droplets. In our experiments, we observed the collision of foam streams induced by flow around the injector resulting in the formation of foum ligaments and the initiation of fragmentation (see Figure 4). This observation suggests that the fragmentation mechanisin in the experiments is ductile. Indeed. liquids like water have extremcly small relaxation times (of order $10^{-12} \mathrm{~s}$ ) and so struin rates far in excess of those measured here would be required to cause britle fracturing of our aqueous foam. The original analysis of the instability of a liquid cylinder issuing from a nozzle was carried out by Lord Rayleigh (reproduced in detail by Chandrasekhar. [1961]. The key result of this analysis is that the cylinder breaks down into symmetric "pinch and swell" structures due to the action of surface tension. The relaxation timescale for ductile fragmentation of a liquid cylinder is given by $\mathrm{T}=\left(\rho \mathrm{r}^{3} / \sigma\right)^{1 / 2}[$ Yanin, 1993], where $r$ is the radius of the liquid cylinder and $\sigma$ is the surface tension of the liquid. Subsequent disintegration of liquid ligaments to globules or droplets was considered by Hinze [ 19.55]. However, neither of these analyses can. as yct. be applied to disintegration of foam ligaments and globules, as foam deformation is influenced by non-Newtonian rheology and planes of weakness resulting from the foam's cellu]ar structure [Kraynik, 1988].

No clear fragmentation front is observed in our flows. Fragmentation is initiated by fluid-mechanical perturbations and occurs throughout the flow in the regions of most rapid gas release where the deformation rate is largest. On fraginentation of foam ligaments, the resulting globules are accelerated to the velocity of the expanding gas flow, as a result of no longer being constrained by the wall shear stress and inertia of the foum continuum. These explosions are markedly different froin those created in explosive boiling experiments [Hill. and Sturtevant, 1990]. The explosively boiling liquids experienced an evaporation wave which propagated down into the liquid colunn at constant velocity with nucleation and fragmentation occurring at the free surface.

\section{Implications for Volcanic Phenomena}

A key characteristic of the natural systems that we have tried to match in these experiments is that the volatile component (largely $\mathrm{H}_{2} \mathrm{O}$ or $\mathrm{CO}_{2}$ in a real volcanic eruption) is in a gaseous state after exsolution but the liquid component (in nature, a silicate liquid \pm crystals), which makes up most of the mass of the system, is essentially entirely condensed, even after the volatile component 
bas nearly completely exsolved. In these respects. the system in these experiments differs significantly from one-component systems [Hill and Sturtevant, 1990] and two-component systems that completely or nearly completely evaporate on decompression.

In order to ensure that the physical processes of explosive volcanism are properly modeled by laboratory simulutions. the experiments must be conducted with similar velocities, accelerations and flow densities to those in large-scale natural flows. Velocities in our experiments approach those of volcanic flows $\left(-10\right.$ to $\left.100 \mathrm{~ms}^{-1}\right)$, as do the accelcrations $(-10$ to $100 \mathrm{~g}$; note that gravity $(\mathrm{lg})$ is unimportant in flows that experience such large accelerations). The high velocitics and accelerations experienced by these flows mean that inertial rather than viscous forces control the dynamics. If the velocities of the laboratory experiments and natural flows are similur, then a necessary consequence is that the timescales in the smaller scale laborulory system are much smaller than the natural timescales. It is indeed the case that the experiments reported here have appropriately short times to scale to typical volcanic flows. The pressure ratio for the experiments ranges from 50 to 100 . comparahle to magmas with a few percent dissolved water (supersaluration pressures $\sim 50$ to $100 \mathrm{MPa}$ ) that disrupt explosively at a few megapascals [Sparks, 1978; Wilson, 1980].

Obviously, the length scales of the volcanic system cannot be reproduced in the lahoratory. However, it is aceepted practice in the study of bubbly liquids and dusty gases that if the transverse dimension of the flow channel is much larger than the smallest bubbles or particles, as it is in our experiments and in the natural flows, then the long-range dynanical interactions between phases that generate a variety of flow scales will be free to act.

Bubble nucleation and growth are ultimately the processes that drive the accelerations observed in our experiments, so scaling of our results to nature requires an evaluation of how they may differ in supersaturated magmas. Molar fractions of volatiles in our experiments (up to $0.1 \mathrm{CO}_{2}$ ) are comparable to those of intermediate to silicic magmas $\left(0.02-0.06 \mathrm{H}_{2} \mathrm{O}\right)$, so the ratio of gas to condensed matter is comparable in the experiments and in nature. The diffusivity of $\mathrm{CO}_{2}$ in $\mathrm{H}_{2} \mathrm{O}\left(2 \times 10^{-9} \mathrm{~m}^{2} \mathrm{~s}^{-1}\right.$ at $20^{\circ} \mathrm{C}$.) is ahout $200 \mathrm{x}$ larger than that of $\mathrm{H}_{2} \mathrm{O}$ in concentrations of ahoul 0.03 in magma at $850^{\circ} \mathrm{C}\left(-10^{-11} \mathrm{~m}^{2} \mathrm{~s}^{-1}\right)$. The diffusively controlled volume growth rate of voids during degussing is proportional to the product of diffusivity and concentration, which could be locally as much as $200 x$ larger than in the magma. The viscosity of water is also many orders of magnitude less than that of magma in explosive eruptions. However, provided the flow regime is inertial, viscosity does not affect the bulk flow dynamics and is therefore not a relevant parameter. Moreover, numerical calculations [Dobran, 1992; Proussevitch et al., 1993; Sparks et al., 1994; Thomas et al., 1994; Barclay et al., 1995] indicate that, even under the conditions of explosive eruption. diffusive bubble growth is not retarded by viscous effects unless magma viscosities exceed about $10^{9} \mathrm{~Pa} \mathrm{~s}$. In the fragmentation region, with pressures of a few megapascals, magnas are not fully degassed and a few tenths of a percent of residual dissolved water are sufficient to keep viscosities at values that would not inhibit explosive expansion rates. Bubble densities in these experiments are thought to be locally higher than the $10^{9} \mathrm{~m}^{-3}$ measured in decompression experiments [Mader ef al.. 1994] hut are still likely to be significantly less than the $2 \times 10^{14} \mathrm{~m}^{-3}$ abserved in laboratory experiments on volcanic glasses [Hunvitz and Navon, 1994], and the nucleation densitics of $3 \times 10^{14}$ $3 \times 10^{16} \mathrm{~m}^{-3}$ inferred from observations of pumice [Whitham and Sparks, 1986; Sparks and Brazier, 1982]. That bublhle densities in the present experiments are possibly several orders of magnitudic smaller than in nature and in decompression experiments on magmatic compositions suggests that gas cvolution rates and accelerations in natural events could he even greater than in these flows.
A possible difference between the experiments and nature concerns the rates of decompression. In the experiments the ambient pressure is $0.1 \mathrm{MPa}$ and the bubbles form from as strongly supersaturated liquid as a consequence of the chemical reaction. The experiments are thus analogous to a sudden large pressure drop and so effectively simulate certain kinds of explosive eruptions such as discrete vulcanian explosions of lava domes. In the case of more sustained eruptions, such as plinian events. decompression occurs progressively as the magma ascends. However, recent experimental data on bubble nucleation in rhyolites [Humitz and Navon, 1994] and modeling of the now regimes in conduits [Sparks et al., 1994] suggest that bubble expansion occurs under conditions of large supersaturations and very rapid decompressions even in sustuined eruptions, which make conditions in the experiments closely compurable to those observed in nature. For example, Sparks et al. [1994] calculate that pressure drops of order $10^{2} \mathrm{MPa}$ can occur in lime periods of order $10 \mathrm{~s}$ in plinian eruptions.

Evidence for the extreme conditions of bubble nucleation and growth in volcanic eruptions can be found in pumice. Bubble densities of $10^{14}$ to $10^{15} \mathrm{~m}^{-3}$ are typical with a wide runge of sizes [Sparks and Brazier, 1982; Whitham and Sparks, 1986]. Many pumice clasts in plinian deposits and ignimbrites display elongate cylindrical or tube vesicles. In extreme cuses they forn fibrous or woody pumice. We suggest that such textures are the direct consequence of the large accelerations that the foumy magma experiences during explosive bubble growth, which results in an elongation of the bubbles as they grow.

In our experiments, water fragments into a spruy in the liquid state, demonstrating that ductile fragmentation induced hy rapid expansion can occur and may provide the fragmentation mechanism in volcanic eruptions also. Foun flows exhibit viscoplastic behavior in that they possess a yield stress below which they do not deform. At shear stresses ahove this value. the viscosity is shear stress dependent [Kraynik, 1988]. We observed accelerations to $15 \mathrm{~m} \mathrm{~s}^{-1}$ in distances of less than $0.5 \mathrm{~m}$ producing extensional strain rates of order $30 \mathrm{~s}^{-1}$. Our experimental liquids are very different to magmas in terins of intrinsic viscosity and surface tension. Assuming that the dynamics of the experimental flows are similar to those found in explosive volcanic eruptions, as suggested ahove, we would expect the deformation rate in the large-scale flows to be of the same order as those seen in our experiments. Silicic magmas exhibit viscoelastic behavior at strain rates comparable to those observed in our experiments [Dingwell and Webb, 1989]. The Maxwell model of linear viscoelastic materials provides a relaxation time $t=\mu / G_{\infty}$, where $m$ is the shear viscosity and $G_{\infty}$ is the shear modulus [Yarin, 1993]. For a magma with a few weight percent dissolved water at eruption temperature $\mu=10^{9} \mathrm{~Pa}$ and $G_{\infty}=10^{10} \mathrm{~Pa}$ so $t=0.1 \mathrm{~s}$ which is of the same order as the inverse strain rate in rapid exsolution. Thus the deformution rate could be sufficient to cause magma to cross the glass transition and so the fragmentation mechanism in an explosive cruption could be brittle.

Models of explosive volcanism have postuluted that magma fragments at a simple downward-propaguting front in almost static foams with vesicularities of 0.7 to 0.8 [Sparks, 1978; Wilson et al., 1980]. In these models flow acceleration occurs after fragmentation. Our experimental simulations cast doubt on this concept. Foam acceleration precedes frugmentution rather than the reverse.

In these flows large gradients of IICl conceutration in the neighborhood of the injection jets generate locally large supersaturation gradients and spatially inhomogeneous liheration of $\mathrm{CO}_{2}$ vapor. Fragmentation occurs throughout the now in the regions of most violent gas release. Thus these chemically generated two-phase flows are intrinsically heterogenerus, and hence model inhomogeneities occurring in real, nuturul systems 
well. Evidence of heterogeneous vesiculation is common in pyroclastic materials.

\section{Summary and Conclusions}

The experiments discussed here produce violently expanding and fragmenting flows with a high degree of reproducibility. They reveal several aspects of the physics of violent degassing within a mixing-limited system. We have shown that the dynamics of the laboratory flows are similar in a number of important respects to the dynamics expected in explosive volcanic eruptions allowing conclusions for the large-scale flows to be drawn. In particular, the results demonstrate the importance of the interaction between mixing and bubble nucleation. The rate of gas evolution is also strongly determined by components due to advection and bubble deformation and in this respect can be regarded as a function of the local flow conditions rather than the fluid properties. Although both the nucleation process and advection may in some respects be different in magmatic systems. degassing in explosively expanding liquids will in general be significantly enhanced by these effects and they should therefore be included in models of explosive eruptions. Furthermore. models of fragmentation in explosive eruptions [Sparks. 1978; Wilson et al., 1980] must be amended to take account of the fact that foam acceleration accompanies fragmentation and that fragmentation may not occur at a well-defined fragmentalion surface.

Acknowledgements. We would like to thank E. Stolper, Y. Zlıang. K. V. Cashman, and an anonynous reviewer for their helpful comments on the manuscript. This work and the salary of J. C. Phillips was funded by grant GR3/8620 from the Natural Environment Research Council. England, and by EC grant PL910499.

\section{References}

Anilkumar, A. V., R. S. J. Sparks and B. Sturtevant, Geological implications and applications of high velocity two-phase flow experiments, J. Volcanol. Geotherm. Res., 56, 145-160. 1993.

Bamford, C. H., and C. F. H. Tripper (Eds.), Comprehensive Chemical Kinetics, Elsevier, New York, 1969.

Barclay, J., D. S. Riley, and R. S. J. Sparks, Analytical models for bubble growth during decompression of high viscosity magmas, $B u l l$. Volcanol., in press, 1995.

Carey, S. N., J. Gardner, H. Sigurdsson, and W. Criswell. Variations in column height and magna discharge during the May 18, 1980 , eruption of Mount St. Helens, J. Volcanol. Geotherm. Res., 43, 99$112,1990$.

Chandrasekhar, S., Hydrodynamic and Hydromagnetic Stability, Clarendon, Oxford, 1961.

Dingwell, D. B., and S. L. Webb, Structural relaxation in silicale melts and non-Newionian melt theology in geologic processes, Phys. Chem. Miner., 16, 508-516, 1989.

Dobran, F., Nonequilibrium flow in volcanic conduits and application to the enuption of Mt. St. Helens on May 18, 1980, and Vesuvius in AD79, J. Volcanol. Geotherm. Res., 49, 285-311. 1992.

Hill, L. G., and B. Sturtevant, An experimental sludy of evaporation waves in a superheated liquid, in Adiabatic Waves in Liquid-Vapor Systems. IUTAM Symposium Görtingen, Germany, 1989, edited by G.
E. A. Meier and P. A. Thompson, pp.25-37. Springer-Verlag, New York, 1990.

Hinze, J. O., Fundamentals of the hydrodynamic mechanism of spliting in dispersion processes, AIChE J., 1,289-295, 19.55.

Hurwitz, S., and $O$. Navon, Bubble nucleation in rhyolitic melts: Experiments at high pressure, temperature and water content, En/Th Planet. Sci. Lett., 122, 267-280, 1994.

Kieffer, S. W. Fluid dynamics of the May 18 blast at Mount St. Helens. U.S. Geol Surv. Prof. Pap., 1250, 379-400. 1981.

Kieffer, S. W., and B. Sturtevant, Laboratory studjes of volcanic jets. J. Geophys. Res., 89, 8253-8268, 1984.

Kraynik, A. M., Foam flows, Arnu. Rev. Fluid Mech., 20, 325-357, 1988.

Mader, H. M., Y. Zliang, J. C. Phillips, R. S. J. Sparks, B. Sturtevant, and E. Stolper, Experimental sinulations of explosive degassing of magnia, Nature, 372, 85-88, 1994.

Proussevitch, A. A., D. C. Sahagian, and A. T. Anderson, Dynanics of diffusive bubble growth in magmas: Isolhermal case, J. Geophys. Res. $98,22,283-22,308,1993$.

Scriven, L. E., On the dynamics of phase growth, Chem. Eng. Sci., 10. L$13,1959$.

Sparks, R. S. J., The dynanics of bubble formation and growth magmas: A review and analysis, J. Volconol. Geothem. Res., 3. I-37, 1978.

Sparks, R. S. J., and S. Brazier, New evidence for derassing procesces during explosive eruptions, Nature, 295, 218-220, 1982.

Sparks, R. S. J., H. Sigurdsson, and L. Wilson, Magma mixing: A mechanism for triggering acid explosive eruptions, Neture. 267,315318, 1977.

Sparks, R. S. J., J. Barclay, C. Jaupart, H. M. Mader, J. Phillips, and B. Sturtevant, Physical aspects of nagma degassing, I. Experimental aw theoretical constraints on vesiculation, Mineral. Soc. All. Rev., 30. 413-445, 1994

Swanger, L. A., and W. C. Rlines, On the necessary conditions for homogeneous nucleation of gas bubbles in liguids., J. Cryst. Growth. $12,323-326,1972$.

Thomas, N., C. Jaupart and S. Vergniolle, On the vesicularity of pumince. J. Geophys. Res., 99, 15,633-15,644, 1994.

Turner, J. S., Buoyancy Effects in Fluids, Cambridge Univ. Press, New York, 1973.

Turner, J. S., H. E. Huppert, and R. S. J. Sparks, An experinemal investigation of volatile exsolution in evolving nagna chambers. $J$. Volcanol. Geotherm. Res., 16, 263-277, 1983.

van Wijngaarden, L., On the growth of sniall cavitation bubbles by convective diffusion, Int. J. Heat Mass Transfer, 10, 127-134, 1967.

Weast, R.C. (Ed.), CRC Handbook of Chemistry and Physics (6tih ed.) CRC Press, Florida, 1983.

Whitham, A. G., and R. S. J. Sparks, Pumice. Bull. Volcanol. 48, 209 223, 1986 .

Wilson, L., Relationships between pressure, volatile content and eject velocity in three types of volcanic explasion, J. Volcanol. Geotherm. Res., 8, 297-313, 1980.

Wilson, L., R. S. J. Sparks, and G. P. L Walker, Explosive volcanis eruptions, $\Gamma \mathrm{V}$, The control of magma properties and conduit geonkerry on eruption column behaviour. Geophys. J. R. Astron. Soc., 63, 117148, 1980.

Yarin, A. L., Free Liquid Jets and Films: Hydrodynamics and Rhentow. Longman, White Plains, N.Y., 1993.

H. M. Mader, J.C.Phillips, and R. S. J. Sparks, Department of Geology, University of Bristol, Bristol, BS8 1RJ, England. (e-mail: H.M.Madere bristol.ac.uk; J.C.Phillips @bristol.ac.uk; Steve.Sparks@bristol.ac.uk)

B. Sturtevant, Graduate Aeronautical Laboratories, California Institute of Technology, Pasadena, CA 91125 . (e-mail: brad@galcit.callech.edar)

(Received September 23, 1994; revised July 31, 1995;

accepted August 10, 1995.) 